


\title{
[Recensão a] MARTINS, Estêvão de Rezende (Coord.) - História Pensada. Teoria e Método na Historiografia Europeia do Século XIX
}

Autor(es): $\quad$ Valente, Isabel Maria Freitas

Publicado por: Imprensa da Universidade de Coimbra

URL persistente:

URI:http://hdl.handle.net/10316.2/36751

DOI:

DOI:http://dx.doi.org/10.14195/1647-8622_11_24

Accessed : $\quad$ 26-Apr-2023 11:51:11

A navegação consulta e descarregamento dos títulos inseridos nas Bibliotecas Digitais UC Digitalis, UC Pombalina e UC Impactum, pressupõem a aceitação plena e sem reservas dos Termos e Condições de Uso destas Bibliotecas Digitais, disponíveis em https://digitalis.uc.pt/pt-pt/termos.

Conforme exposto nos referidos Termos e Condições de Uso, o descarregamento de títulos de acesso restrito requer uma licença válida de autorização devendo o utilizador aceder ao(s) documento(s) a partir de um endereço de IP da instituição detentora da supramencionada licença.

Ao utilizador é apenas permitido o descarregamento para uso pessoal, pelo que o emprego do(s) título(s) descarregado(s) para outro fim, designadamente comercial, carece de autorização do respetivo autor ou editor da obra.

Na medida em que todas as obras da UC Digitalis se encontram protegidas pelo Código do Direito de Autor e Direitos Conexos e demais legislação aplicável, toda a cópia, parcial ou total, deste documento, nos casos em que é legalmente admitida, deverá conter ou fazer-se acompanhar por este aviso.




fazer história contemporânea

ESTUDOSDOSÉCULO

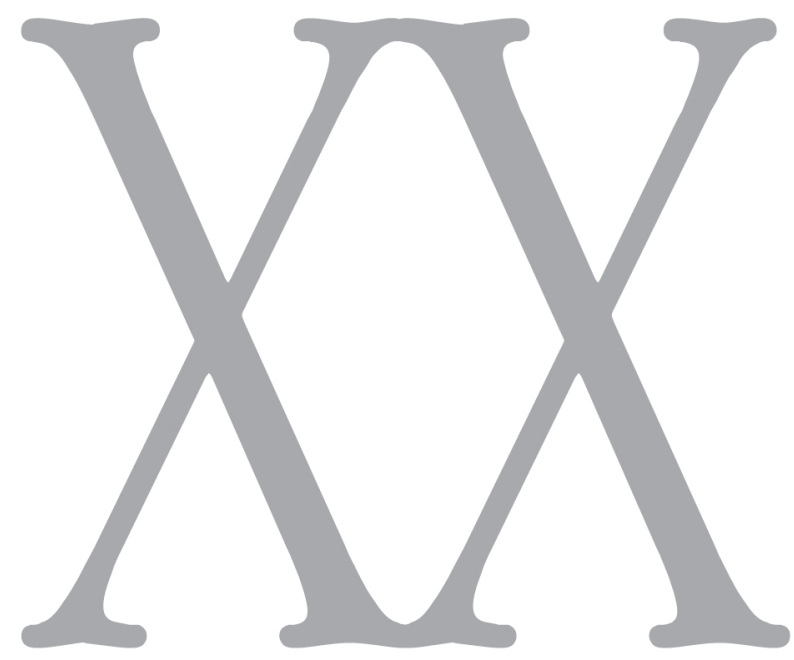

número 11 • 2011




MARTINS, Estêvão de Rezende (Coord.) - História Pensada. Teoria e Método na Historiografia Europeia do Século XIX. Sáo Paulo: Editora Contexto, 2010. 248p. ISBN 978-85-7244-468.

A presente obra é o resultado de um projecto de investigação que visa compreender os problemas metodológicos inerentes à produção do discurso científico em História. Contando com a participação de vários especialistas brasileiros, que integram um grupo de trabalho (GT) da Associação Nacional da História, este livro tem como principal objectivo despertar a consciência crítica da comunidade académica para o "Renascimento da História como Ciência”.

Como bem se sabe, o renascimento da História organiza-se e estrutura-se na passagem do Iluminismo para o Romantismo e vai-se consolidando ao longo do século XIX nos cenários do positivismo, do historicismo e das escolas metódicas. O mesmo é dizer que a "disciplina da historiografia, no sentido contemporâneo do termo, surgiu na transição do século XIX, mediante um primeiro corpo de regras e normas metodológicas fixado sob influência do positivismo e do historicismo".

Deve acentuar-se, porém, que a procura, a busca de compreensão da realidade presente conduz-nos inevitavelmente a questionar o passado numa tentativa de compreensão do presente e de "prefiguração do futuro".

Michelet, numa obra publicada no século XIX, lembra essa realidade nestas palavras: "aquele que quiser atar-se ao presente não compreenderá nunca esse mesmo presente.” A obra em análise insere-se plenamente neste plano epistemológico.

Neste quadro não deixa de ser importante realçar que a relaçáo entre o historiador e o seu tempo é uma das questôes cruciais do debate historiográfico, metodológico e teórico da História.

É inegável que o livro - História pensada. Teoria e método na Historiografia europeia do século XIX - visa proporcionar uma leitura do processo de consolidação do pensamento histórico como ciência através da pena de protagonistas fundamentais e cujos textos dificilmente se encontram traduzidos em português. Deste modo, o leitor tem acesso às obras de: Thomas Carlyle, Johann Gustav Droysen, Ernst Bernheim, Wilhelm von Humboldt, Theodor Mommsen, Karl Lamprescht, George Macaulay Trevelyan, Jacob Burckhardt, Leopold von Ranke e Henry Thomas Buckle precedidas de um comentário que é simultaneamente introduçáo ao autor e explicaçáo do texto.

É ainda de sublinhar que aliada à questão científica a questão didáctica e pedagógica perpassa, aliás, toda a obra, culminando com a organização dos textos escolhidos em três capítulos que correspondem a três eixos temáticos. A saber:

- A História faz sentido

- O Sentido produzido pela História

- A História e os seus campos

O livro conta com uma introdução da autoria de Estêvão de Rezende Martins, sempre problematizador e fértil em oportunos desafios.

Este volume concorre tanto para uma leitura retrospectiva quanto prospectiva da natureza do conhecimento histórico, relevando as questóes de problematização e cientificidade do mesmo.

Por outro lado, estas reflexôes críticas dos ensaios constituem um útil manancial de visóes e abordagens à "maneira aristotélica, da pesquisa e da formação de pesquisadores" sobre uma das problemáticas fulcrais da obra - fornecer 
instrumentos para uma avaliação crítica das obras historiográficas bem como das matizes historiográficas contemporâneas.

Com o mesmo rigor e amplo escopo da produção histórica de Estêvão de Rezende Martins, a presente publicação apresenta-se como uma boa base para reflexóes mais aprofundadas sobre processos fulcrais da hodiernidade histórica.

Isabel Maria Freitas Valente Bolseira de Doutoramento da FCT/CEIS20 Membro Team Europe

ANTUNES, João Lobo - Egas Moniz. Uma biografia. $1^{a}$ ed. Lisboa: Gradiva, 2010. 375 p. ISBN 978-989-616-398-3.

Não é difícil compulsar duas dezenas de textos do autor sobre o biografado sem, no entanto, pretender esgotar tudo o que tem publicado a esse respeito: entrevistas, artigos, capítulos em livros, prefácios e catálogos de exposiçóes in memoriam ${ }^{l}$.

\footnotetext{
${ }^{1}$ Destacamos: ANTUNES, Joâo Lobo - "As cartas de Egas Moniz para Almeida Lima”. In ANTUNES, João Lobo - Um modo de ser. 10a ed. Lisboa: Gradiva, 1996. ISBN 978-972-662-499-8. p. 173- 201; "Egas Moniz homem de letras”. In ANTUNES, João Lobo - Numa cidade feliz. Lisboa: Gradiva, 1999. ISBN 978-972-662-704-3. p. 213-223; "Pedro Almeida Lima”. In ANTUNES, João Lobo - Um modo de ser. 10a ed. Lisboa: Gradiva, 1996. p. 139-145; "Psicocirurgia - Uma história". In ANTUNES, João Lobo - Numa cidade feliz. Lisboa: Gradiva, 1999. p. 225-248; "Egas Moniz - uma palavra sobre o Outro”. In ALVES, M. Valente - 1911-1999. O ensino médico em Lisboa no início do Século. Sete artistas contemporâneos evocam a geração de 1911. Lisboa: Fundação Calouste Gulbenkian, 1999. Catálogo da Exposiçấo. 431 p.; e "Egas Moniz hoje”. In ANTUNES, João Lobo - O Eco Silencioso. Lisboa:
}

Trata-se, pois, de um especialista que soma à sua condição de neurocientista como Egas Moniz o foi avant la lettre, as de médico, político e escritor. De certo modo, o som dos seus passos soa numa sala de eco onde se podem adivinhar ainda as passadas de seu pai, João Alfredo Lobo Antunes; seu tio-avô, Pedro Almeida Lima; e do próprio Egas Moniz. Esta é pois uma biografia de um próximo de próximos, profundo conhecedor dos meandros da neurologia, da cultura e da política em que o biografado habitou; um texto povoado por sucessivas idas e voltas entre o reconhecido fascínio que a personagem exerce sobre o biógrafo, e o esforço de distanciamento necessário para dar conta das dimensóes críticas que asseguram a rejeição do modo hagiográfico.

Esta é também uma biografia que reflecte, para além da reunião de múltiplas e esparsas anotaçóes que foi escrevendo acerca do Mestre Egas, uma série de comentários à vastidão das leituras que fez acerca do que se foi publicando sobre a Angiografia Cerebral, a Leucotomia Préfrontal, e sobre a sua figura, as simplificaçôes, inexactidóes, distorçóes e mentiras.

A estruturaçáo do texto obedece a um esquema quase cronológico, em que são valorizadas fases da vida, actividades e episódios geralmente omitidos ou desvalorizados no acervo de textos de carácter biográfico, biografias científicas e outros ensaios afins, publicados até hoje, incluindo naturalmente a produção do próprio Egas Moniz.

O Mestre Egas que sai da pena de João Lobo Antunes é de uma humanidade mais consentânea com as ideias que temos sobre os homens, contraditório, ambicioso,

Gradiva, 2008. 262 p. ISBN 978-989-616-281-8. p. 97-109. 